\title{
Chronic Quinolinic Acid Lesions in Rats Closely Resemble Huntington's Disease
}

\author{
M. Flint Beal, ${ }^{1}$ Robert J. Ferrante, ${ }^{1,2}$ Kenton J. Swartz, ${ }^{1,3}$ and Neil W. Kowall ${ }^{1}$ \\ 'Neurochemistry and Experimental Neuropathology Laboratories, Neurology Service, Massachusetts General Hospital and \\ Harvard Medical School, Boston, Massachusetts 02114, ${ }^{2} \mathrm{C}$. S. Kubik Laboratory of Neuropathology, James Homer Wright \\ Laboratories, Massachusetts General Hospital, Boston, Massachusetts 02114, and 3Program in Neuroscience, Harvard \\ Medical School and Harvard University, Boston, Massachusetts 02115
}

\begin{abstract}
We previously found a relative sparing of somatostatin and neuropeptide $Y$ neurons 1 week after producing striatal lesions with NMDA receptor agonists. These results are similar to postmortem findings in Huntington's disease (HD), though in this illness there are two- to threefold increases in striatal somatostatin and neuropeptide $Y$ concentrations, which may be due to striatal atrophy. In the present study, we examined the effects of striatal excitotoxin lesions at 6 months and 1 $y r$, because these lesions exhibit striatal shrinkage and atrophy similar to that occurring in HD striatum. At 6 months and $1 \mathrm{yr}$, lesions with the NMDA receptor agonist quinolinic acid (QA) resulted in significant increases (up to twofold) in concentrations of somatostatin and neuropeptide $Y$ immunoreactivity, while concentrations of GABA, substance $P$ immunoreactivity, and ChAT activity were significantly reduced. In contrast, somatostatin and neuropeptide $Y$ concentrations did not increase 6 months after kainic acid (KA) or $\alpha$-amino-3-hydroxy-5-methyl-isoxazole-4-propionic acid (AMPA) lesions. At both 6 months and $1 \mathrm{yr}$, QA lesions showed striking sparing of NADPH-diaphorase neurons as compared with both AMPA and KA lesions, neither of which showed preferential sparing of these neurons. Long-term QA lesions also resulted in significant increases in concentrations of both 5-HT and 5-hydroxyindoleacetic acid (HIAA), similar to findings in HD. Chronic QA lesions therefore closely resemble the neurochemical features of HD, because they result in increases in somatostatin and neuropeptide $Y$ and in 5-HT and HIAA. These findings strengthen the possibility that an NMDA receptor-mediated excitotoxic process could play a role in the pathogenesis of HD.
\end{abstract}

Huntington's disease (HD) is an autosomal dominant inherited neurodegenerative disorder that usually begins in midlife and is characterized by involuntary choreiform movements, cognitive impairment, and emotional disturbance (Bruyn, 1968). The major site of pathology in HD is the striatum, where up to $90 \%$ of the neurons may be depleted (Vonsattel et al., 1985). Within the striatum there is differential vulnerability of neuronal

\footnotetext{
Received Aug. 22, 1990; revised Dec. 26, 1990; accepted Jan. 4, 1991.

The secretarial assistance of Sharon Melanson is gratefully acknowledged. This work was supported by NINDS Grant 16367 (Huntington's Disease Center Without Walls).

Correspondence should be addressed to Dr. M. Flint Beal, Neurology Research 4, Massachusetts General Hospital, Boston, MA 02114.

Copyright (C) 1991 Society for Neuroscience $0270-6474 / 91 / 111649-11 \$ 03.00 / 0$
}

populations. Striatal medium-sized spiny neurons containing the neurochemical markers GABA, substance $P$, dynorphin, and enkephalin are preferentially affected (Beal and Martin, 1986; Ferrante et al., 1987b; Beal et al., 1988b). In contrast, mediumsized aspiny neurons containing the neuropeptides somatostatin and neuropeptide $Y$, and large aspiny neurons containing $\mathrm{ChAT}$ activity, are spared (Dawbarn et al., 1985; Ferrante et al., 1985, 1987a; Beal et al., 1988b). Dopaminergic and serotonergic afferent projections are also spared (Spokes, 1980; Beal et al., 1990b).

A suitable animal model of HD must replicate these features. Initial studies with kainic acid (KA)-induced lesions showed a striking resemblance to HD (Coyle and Schwarcz, 1976; McGeer and McGeer, 1976). Intrastriatal injections resulted in neuronal loss and gliosis, with reductions in markers of intrinsic striatal neurons, yet a preservation of dopaminergic afferents. We found, however, that these lesions were an imperfect model of HD, because they resulted in a significant depletion of somatostatin levels and a loss of somatostatin neurons (Beal et al., 1985). We subsequently found that lesions produced by NMDA receptor agonists such as quinolinic acid (QA) provided a better model of $\mathrm{HD}$, because they result in relative sparing of somatostatin and neuropeptide $Y$ levels, despite significant depletions of both GABA and substance P levels (Beal et al., 1986a, 1989b). In $\mathrm{HD}$, however, there are two- to threefold increases in concentrations of somatostatin and neuropeptide $Y$, rather than the mere preservation of levels observed 1 week after lesions with NMDA receptor agonists (Beal et al., 1989b). It is possible that the increased levels reflect preservation of somatostatin-neuropeptide $Y$ neurons, in combination with striatal atrophy and shrinkage. Following long-term excitotoxin lesions, there are marked striatal shrinkage and atrophy (Zaczek et al., 1978; Isacson ct al., 1984, 1985; Bjorklund et al., 1986). In the present study, we therefore examined the effects of lesions at both 6-month and 1-yr survival times.

\section{Materials and Methods}

KA and QA were obtained from Sigma (St. Louis, MO), while $\alpha$-amino3-hydroxy-5-methyl-isoxazole-4-propionic acid (AMPA) was obtained from Research Biochemicals (Wayland, MA). Male Sprague-Dawley rats (Charles River) weighing 150-175 gm were anesthetized with pentobarbital $(50 \mathrm{mg} / \mathrm{kg}$, i.p.). Compounds were dissolved in phosphatebuffered saline $(\mathrm{pH}, 7.4)$ and were injected in a volume of $1 \mu$ linto the left striatum at the coordinates $8.4 \mathrm{~mm}$ anterior, $2.6 \mathrm{~mm}$ lateral, and $4.5 \mathrm{~mm}$ ventral to the dura (Beal et al., 1989b). Injections were made with a $10-\mu 1$ Hamilton syringe fit with a 30 -gauge blunt-tipped needle. 


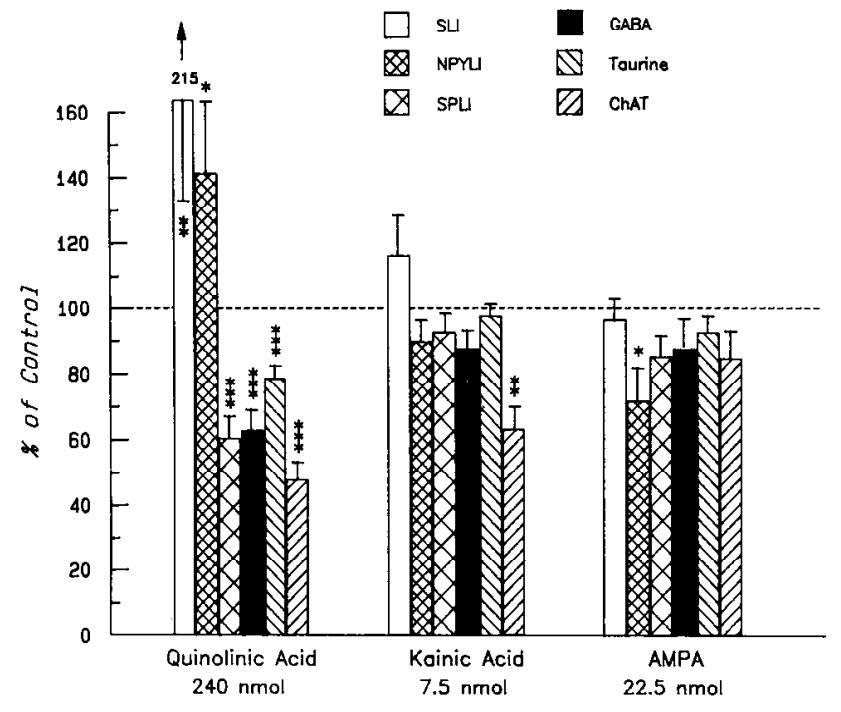

Figure 1. Effects of QA, KA, and AMPA striatal lesions at 6 months. The QA lesions resulted in significant increases in both somatostatin $(S L I)$ and neuropeptide $\mathrm{Y}(N P Y L I)$ concentrations while substance $\mathrm{P}$ (SPLI), GABA, taurine, and ChAT activity were significantly reduced. Neither KA nor AMPA lesions resulted in significant increases in somatostatin or neuropeptide $Y$ concentrations. ${ }^{*}, P<0.05$; ${ }^{* *}, P<0.01$; $* * *, P<0.001$.

All injections were made over $1 \mathrm{~min}$, and the needle was left in place for a further $2 \mathrm{~min}$ before being slowly withdrawn.

Three groups of eight animals were lesioned with QA $(240 \mathrm{nmol})$, AMPA $(22.5 \mathrm{nmol})$, or KA $(7.5 \mathrm{nmol})$. Thesc animals werc killed 6 months after lesions were produced. Two additional groups of eight animals lesioned with $240 \mathrm{nmol}$ of QA were allowed to survive for 1 week or 1 yr. Following death, the brains were chilled, and the anterior striatum and overlying cerebral cortex were dissected from a 2-mmthick slice, as previously described (Beal et al., 1986a). Care was taken to exclude the globus pallidus. The left and right striata were placed in $1 \mathrm{ml}$ chilled $0.1 \mathrm{~N} \mathrm{HCl}$. In the animals that survived for $1 \mathrm{yr}$, the midbrain (substantia nigra) was also dissected: Tissue samples were subsequently sonicated, extracted, and assayed for somatostatin-like immunoreactivity, neuropeptide Y-like immunoreactivity, substance P-like immunoreactivity, and GABA as previously described (Arnold et al., 1982; Beal et al., 1986b; Beal and Mazurek, 1987; Ellison et al., 1987a). Monoamines and their metabolites were measured by high-performance liquid chromatography with 16-electrode clcctrochcmical detcction (ESA CEAS, 55-0650; Matson et al., 1987). Kynurenic acid was measured by highperformance liquid chromatography with fluorescence detection (Swartz et al., 1990). Choline acetyltransferase activity measurements were made using the Fonnum method (Fonnum, 1969). Protein measurements were made on the sonicate using a fluorometric assay (Bohlen et al., 1973). The neurochemical measurements were compared with the unlesioned (control) side and are expressed as percentages of control. We have previously found that the right (control) values do not differ from saline controls (Beal et al., 1989b). The results are expressed as the mean \pm standard error of the mean. Comparisons were made using Student's $t$ test (two-tailed) or one-way analysis of variance (ANOVA).

A total of 24 animals were used for histologic studies. Six animals with QA lesions and three each with either AMPA or KA lesions were examined at 6 months. Three additional groups of four animals wcre lesioned with QA, KA, or AMPA and were examined at 1 yr. Initially there were equal numbers in the 1-yr lesion groups, but only two KAand two AMPA-lesioned animals survived. Animals were killed using deep anesthesia with pentobarbital and perfused via an intracardiac cannula with $0.25 \%$ sodium nitrite in $0.9 \%$ saline followed by fixation with $4 \%$ paraformaldehyde and $0.02 \%$ glutaraldehyde in $0.1 \mathrm{M}$ phosphate buffer (pH, 7.3). Brains were postfixed overnight and then removed, blocked and washed in phosphate buffer, and cut at $50-\mu \mathrm{m}$ intervals with a vibratome. Sections were then stained for NADPHdiaphorase in combination with Nissl, or for NADPH-diaphorase in

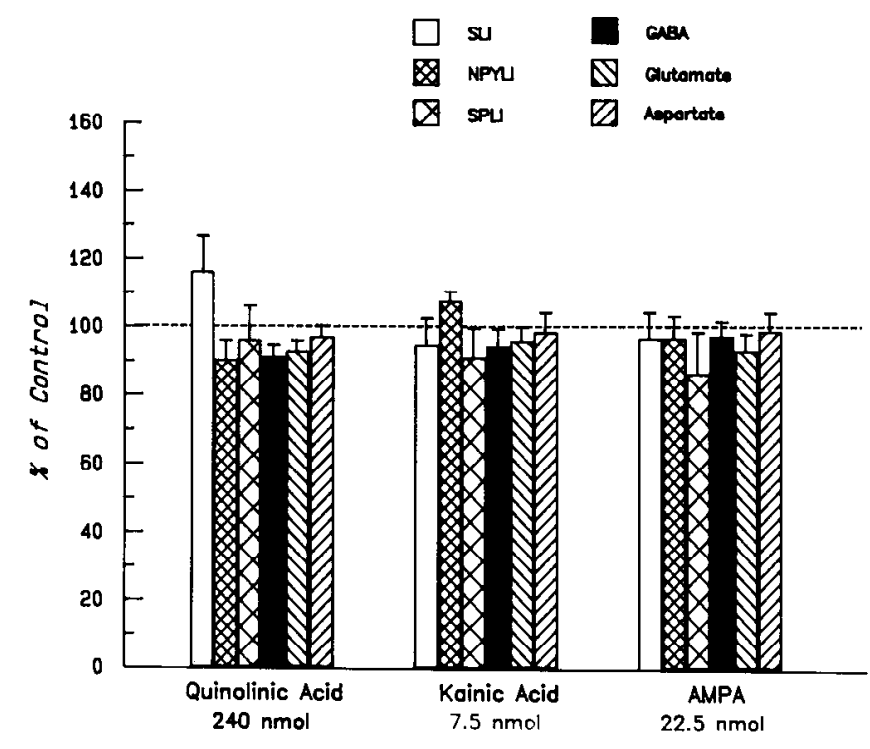

Figure 2. Neurochemical measurements in cerebral cortex overlying 6-month striatal excitotoxin lesions. There were no significant changes in any of the compounds examined. Abbreviations are as in Figure 1.

combination with immunocytochemical staining for Met-enkephalin (ENK), as previously described (Beal et al., 1989b).

Examination of the lesions at both 6 months and 1 yr showed a marked shrinkage of the lesioned striatum. Total protein measurements on the side of the lesion were reduced by approximately $50 \%$. The large lesion core, in which there are intense gliosis and few remaining neurons at 1 week, was largely resorbed. The needle track and a small surrounding necrotic region could usually be identified. This was surrounded by a large region of partial neuronal loss and gliosis, which we term the transition zonc. This extended to an arca of relatively normal-appearing striatum adjacent to the corpus callosum at the periphery of the lesion. Within the transition zone, neuronal counts were made by two independent observers. A $350 \times 500-\mu \mathrm{m}$ field at $250 \times$ magnification was counted, using an eyepiece graticule. Fields in the transition zone of the lesioned striatum were compared with fields in the same location in the contralateral control (unlesioned) striatum. Counts were made in six fields in each animal and were averaged. Counts were expressed as the ratio of NADPH-diaphorase-reactive neurons to total neurons (Nissl stained) or to the number of Met-enkephalin neurons. Statistical comparisons were made by ANOVA with post hoc analysis using the Sheffe $F$ test or the nonpaired Student's $t$ test. The results are expressed as the mean \pm standard error of the mean.

\section{Results}

The neurochemical effects of QA, KA, and AMPA lesions at 6 months are shown in Figure 1. We chose doses of each toxin that our previous experience indicated would produce lesions of comparable size (Beal et al., 1989b). Nevertheless, in the present experiments the lesions following KA and AMPA were less severe than those produced by QA, because neither substance $P$ nor GABA were significantly reduced at 6 months following the lesions. Histologic evaluation verified that lesions were present in all groups. The absence of significant reductions in GABA and substance $\mathrm{P}$ appeared to be due to the overall shrinkage of the striatum following the lesions.

The QA lesions resulted in significant depletions of both substance $\mathrm{P}$ and GABA of about $40 \%$. Taurine concentrations were reduced approximately $20 \%$. Somatostatin and neuropeptide $Y$ concentrations were significantly increased by $115 \%$ and $41 \%$, respectively. In contrast there were no significant increases following KA or AMPA lesions, and indeed, AMPA lesions re- 


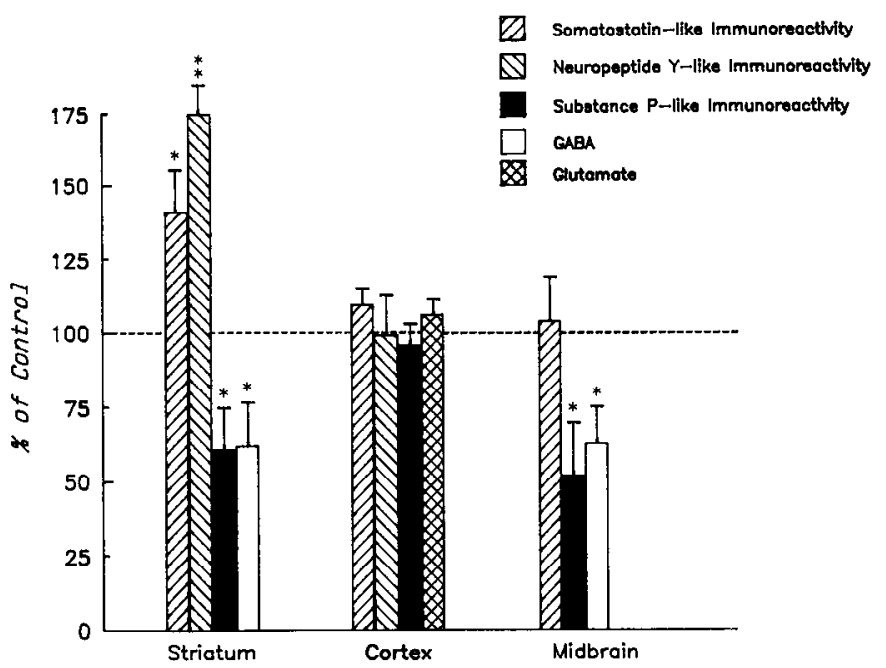

Figure 3. Effects of QA striatal lesions at 1 yr. Somatostatin and neuropeptide $\mathrm{Y}$ concentrations were significantly increased in the striatum, while GABA and substance $P$ were significantly reduced in both the striatum and midbrain. There were no significant changes in overlying cerebral cortex. ${ }^{*}, P<0.05 ;{ }^{* *}, P<0.01$.

sulted in a significant, $29 \%$, reduction in neuropeptide $Y$ concentrations. There were no significant changes in levels of neuropeptides or amino acid neurotransmitters in the overlying cerebral cortex (Fig. 2). Striatal ChAT activity was significantly decreased by $52 \%$ following QA lesions and by $36 \%$ following KA lesions.

The neurochemical effects of QA lesions at 1 yr are shown in Figure 3. Similar to the 6-month lesions, there were significant $40 \%$ reductions in GABA and substance $P$, while somatostatin and neuropeptide $Y$ were significantly increased by $41 \%$ and $74 \%$, respectively. There were no significant changes in neurochemical markers in the overlying cortex, while both substance $P$ and GABA concentrations were significantly reduced in the midbrain ipsilateral to the striatal lesions.

Changes in dopamine (DA), 5-HT, and their metabolites were compared in QA lesions at 1 week and at 1 yr (Fig. 4). The 1 -week lesions resulted in significant increases in homovanillic acid (HVA) and 5-hydroxyindoleacetic acid (HIAA), yet no changes in DA and 5-HT concentrations, resulting in significant increases in the ratios of HVA and HIAA to their parent compounds. At $1 \mathrm{yr}$, there were significant increases in concentrations of both 5-HT and HIAA, but no significant changes in DA or HVA. Similar changes were observed following QA, AMPA, and KA lesions at 6 months (Fig. 5). There were no significant changes in concentrations of uric acid, xanthine, tyrosine, tryptophan, or kynurenine at 6 months in the animals lesioned with QA and KA (data not shown). Kynurenic acid concentrations were significantly increased in animals lesioned with QA at 6 months. The concentration on the unlesioned side was $273.3 \pm 40.9 \mathrm{fmol} / \mathrm{mg}$ protein, compared with $590.8 \pm$ $127.9 \mathrm{fmol} / \mathrm{mg}$ protein on the lesioned side $(n=7 ; p<0.03)$.

Chronic QA lesions at both 6 months and $1 \mathrm{yr}$ resulted in marked striatal atrophy and shrinkage. No discernable histologic or morphologic differences could be identified between 6-month and 1-yr QA lesions. The marked atrophy is shown histologically in Figure 6. Despite marked gliosis and neuronal depletion, there was a relative preservation of NADPH-diaphorase neurons within regions that showed a depletion of Nissl-

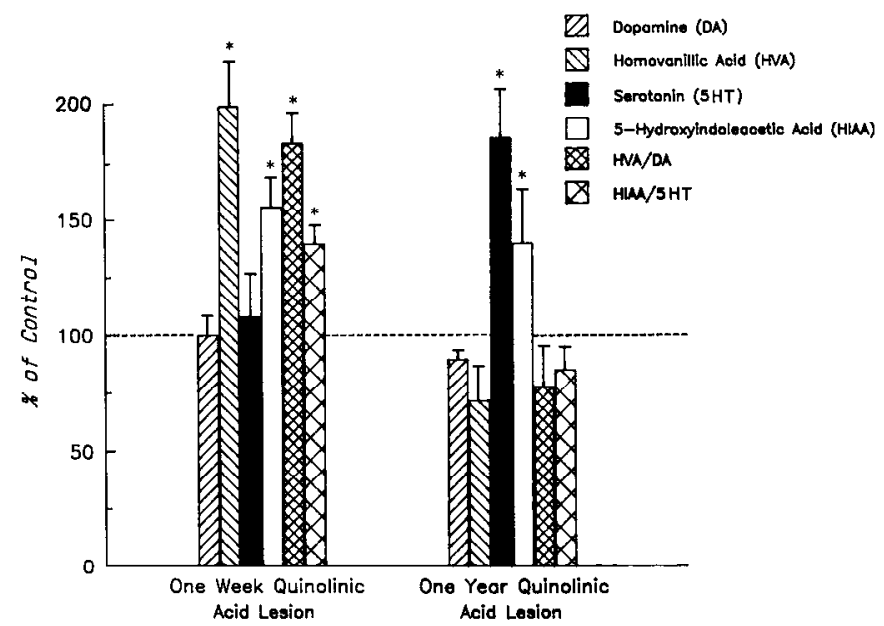

Figure 4. Effects of QA striatal lesions at 1 week and 1 yr on monoamines and their metabolites. At 1 week, both HVA and HIAA were significantly increased, with no change in DA anc 5-HT, whereas at 1 yr only HIAA and 5-HT were significantly increased. ${ }^{*}, P<0.05$.

stained neurons (Fig. 7A-D). KA lesions at 6 months and $1 \mathrm{yr}$ showed a comparable degree of striatal atrophy (Fig. 6). In contrast to QA lesions, these lesions did not show relative sparing of NADPH-diaphorase neurons within the areas in which there was a depletion of Nissl-stained neurons (Fig. $8 A-D$ ). A camera lucida drawing of NADPH-diaphorase neurons in 6-month KAand QA-lesioned striata is shown in Figure 9, demonstrating relative sparing of NADPH-diaphorase following the QA lesion. In addition, there was qualitative sparing of large neurons with QA, KA, and AMPA lesions, though this was not quantitated.

ENK staining is a selective marker for striatal medium-sized spiny neurons, which are depleted by excitotoxin lesions. We

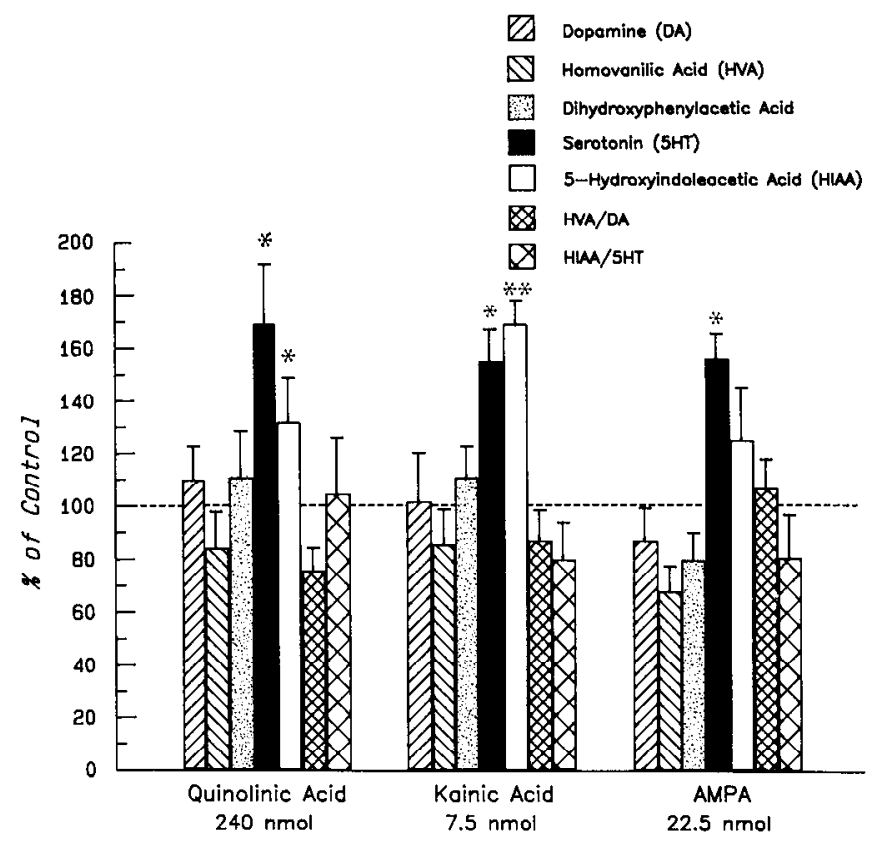

Figure 5. Effects of QA, KA, and AMPA striatal lesions on monoamines and their metabolites at 6 months. Significant increases in 5-HT were seen with all three compounds, while HIAA was significantly increased with both QA and KA lesions. ${ }^{*}, P<0.05$; ${ }^{* *}, P<0.01$. 
Figure 6. Photomicrographs of Nisslstained coronal sections of striatal lesions produced by QA $(A)$ and $\mathrm{KA}(B)$ in rats killed at $1 \mathrm{yr}$. The notch in cortex identifies the lesioned side. Note the marked striatal atrophy in both $A$ and $B$ as compared to the contralateral side. Magnification, $1 \times$.

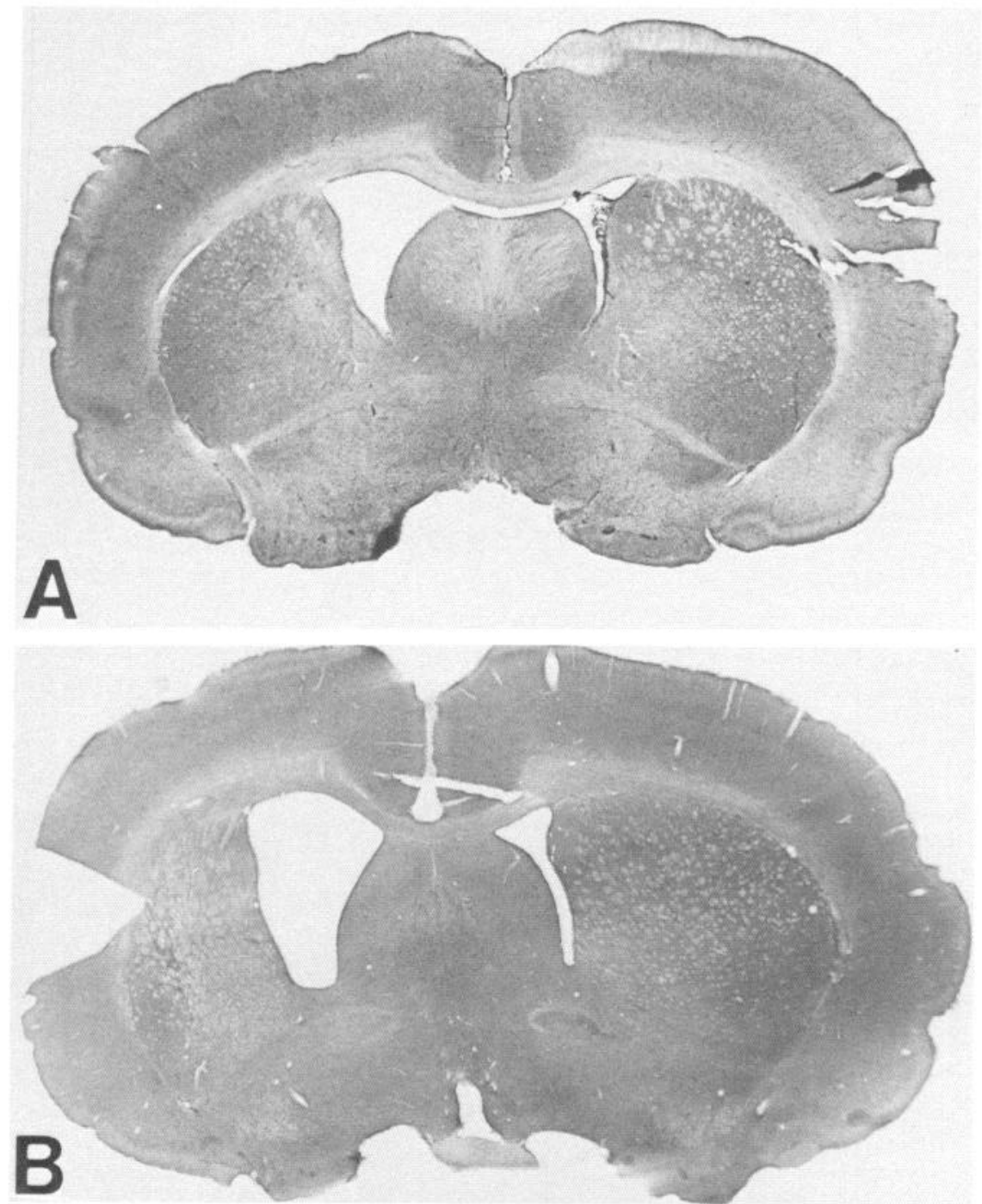

therefore examined whether NADPH-diaphorase neurons were spared relative to ENK-stained neurons in the 6-month lesions. Camera lucida drawings of both QA and KA lesions comparing ENK-stained neurons to NADPH-diaphorase neurons are shown in Figure 10. The QA lesions resulted in sparing of NADPHdiaphorase neurons relative to ENK neurons; however, no such sparing was seen with the KA lesions. Representative sections of ENK immunocytochemistry combined with NADPH-diaphorase staining following both QA and KA lesions are shown in Figure 7, $E$ and $F$, and Figure $8, E$ and $F$. The numbers of NADPH-diaphorase neurons following QA lesions relative to ENK neurons or Nissl-stained neurons are shown in Tables 1 and 2, respectively. QA lesions resulted in marked sparing, but neither KA nor AMPA lesions showed relative sparing of NADPH-diaphorase neurons.

\section{Discussion}

Neurodengerative illnesses such as Alzeimer's disease, Parkinson's disease, and HD are characterized by gradually evolving selective neuronal death. As yet, the mechanisms by which selective neuronal death occurs are unknown. Animal models using neurotoxins that produce similar patterns of neuronal de- generation may yield important clues to the etiology of these illnesses. In HD, much interest has been focused on the similarities between striatal lesions produced with excitatory amino acid analogs, and the neurochemical and neuropathological features of HD.

In 1976, it was demonstrated that intrastriatal injection of the powerful neuroexcitant KA leads to the degeneration of striatal neurons (Coyle and Schwarcz, 1976; McGeer and McGeer, 1976). The lesions were confined to neuronal cell bodies, did not affect traversing or afferent fibers, and appeared to spare non-neuronal elements such as glia. The parallels extended to subtle aspects of the neuropathology, such as differential sparing of large striatal neurons. It was therefore proposed that an endogenous "excitotoxin" might play a role in the pathogenesis of HD.

KA is isolated from the seaweed Diginea simplex and is not present in mammalian brain. Furthermore, we and others found that lesions with KA do not spare somatostatin-neuropeptide Y neurons, which are spared in HD (Araki et al., 1985; Beal et al., 1985, 1986a). Recent work with excitatory amino acid analogs has focused on compounds known to be present in mammalian brain. Schwarcz and colleagues found that lesions with 

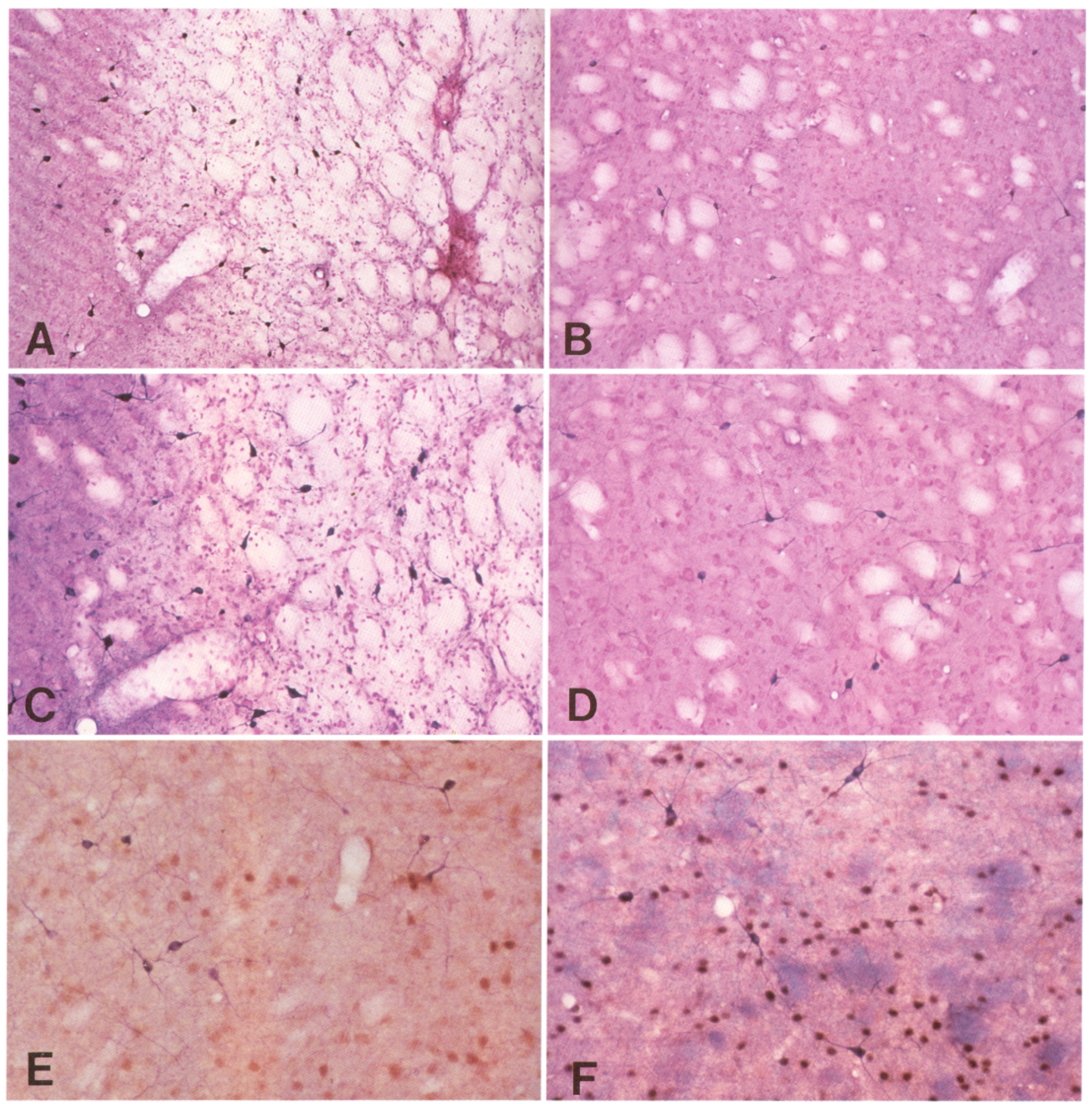

Figure 7. Combined Nissl and NADPH-diaphorase staining of a 1-yr QA-lesioned rodent striatum (Fig. $6 A$ ) in $A$ and $C$ with corresponding areas of contralateral unlesioned striatum in $B$ and $D$. In $A$, a needle track (far right) is surrounded by a small lesion core that extends into a region of marked neuronal depletion (transition zone) in which NADPH-diaphorase neurons (dark blue neurons with dendritic arbors) are strikingly preserved. This region continues into a more normal zone (far left) in which Nissl-stained neurons appear in the same frequency as in the contralateral side. A higher-power photomicrograph of the transition zone is represented in $C$, with control striatum in $D$. Combined ENK and NADPH-diaphorase staining of QA-lesioned striatum is demonstrated in $E$, and contralateral unlesioned striatum in $F$. Brown perikarya are ENK-positive neurons, while dark blue neurons with secondary and tertiary dendritic arbors are NADPH-diaphorase neurons. There is a significant reduction of both neuronal and neuropil ENK staining in the QA-lesioned striatum as compared to the contralateral side with a preservation of NADPH-diaphorase neurons. Magnification: $A$ and $B, 4 \times ; C-F, 10 \times$.

the tryptophan metabolite QA resulted in selective neuronal damage similar to that seen in HD (Schwarcz et al., 1983, 1984).

Although QA lesions have been used to model HD, they are not ideal in that one is using an acute injection to mimic a slowly progressive degenerative illness. The acute injection of QA or other excitotoxins results in a high concentration of the excitotoxin, which then diffuses outwards, producing a concentration gradient. The area immediately surrounding the injection 

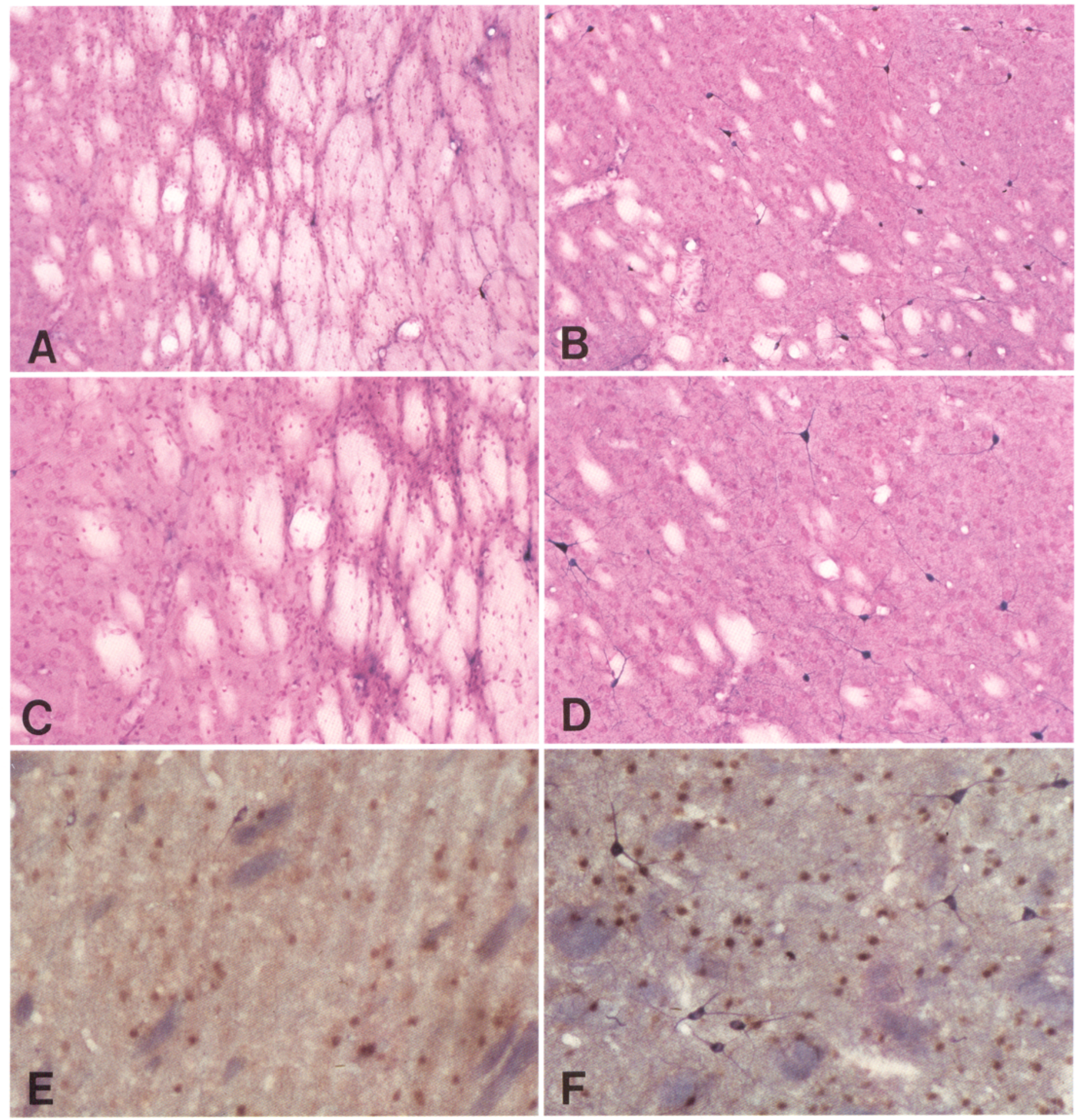

Figure 8. Combined Nissl and NADPH-diaphorase staining of a 1-yr KA-lesioned rodent striatum (Fig. $6 B$ ) in $A$ and $C$, with corresponding areas of the contralateral unlesioned striatum in $B$ and $D$. There is marked neuronal loss without NADPH-diaphorase cell sparing as compared to QA (Fig. 7A,C). Combined ENK and NADPH-diaphorase staining in $E$ demonstrates that both neurochemical subsets of striatal neurons are depleted. The contralateral unlesioned striatum is shown in $F$. Magnification: $A$ and $B, 4 \times ; C-F, 10 \times$.

site is characterized by intense gliosis and indiscriminate depletion of all neuronal types. We have termed this zone the lesion core (Beal et al., 1989b). Surrounding this zone is an area of gliosis and partial neuronal loss we have termed the transition zone, because it extends to the region in which neurons appear undamaged. We have utilized both neurochemical dose-re- sponse studies of excitotoxins and histologic studies to demonstrate relative sparing with medium-sized aspiny neurons containing somatostatin and neuropeptide $\mathrm{Y}$ (which are NADPH-diaphorase positive) within the transition zone of QA lesions (Beal et al., 1986a, 1989b). We found that lesions with the NMDA receptor agonists L-homocysteic acid and $N$-methyl- 
Table 1. NADPH-diaphorase and ENK neuron counts in the transition zone of chronic exitotoxin lesions

\begin{tabular}{lcc}
\multicolumn{1}{c}{ QA } & KA \\
\hline NADPH-diaphorase & & \\
$\quad$ Control & $6.0 \pm 0.2$ & $5.8 \pm 0.5$ \\
Lesion & $14.0 \pm 0.6^{* * *}$ & $2.1 \pm 0.3^{* *}$ \\
ENK & & \\
Control & $95.6 \pm 3.5$ & $126.3 \pm 7.2$ \\
Lesion & $34.8 \pm 2.2^{* * *}$ & $61.8 \pm 10.7^{* * *}$ \\
\% NADPH-diaphorase/ENK & & \\
Control & $6.5 \pm 0.3$ & $4.8 \pm 0.5$ \\
Lesion & $44.4 \pm 2.8^{* * *}$ & $2.3 \pm 0.5^{* *}$
\end{tabular}

Six animals were examined with $\mathrm{QA}$, and two with KA. Data are the mean \pm SEM; ${ }^{* *}, P<0.01 ;{ }^{* * *}, P<0.001$.

$\mathrm{D}, \mathrm{L}$-aspartate also produce relative sparing of NADPH-diaphorase neurons (Beal et al., 1989b, 1990a). Dose-response studies in both striatal cell cultures and organotypic striatal cultures have confirmed a relative, but not absolute, sparing of NADPHdiaphorase neurons following lesions with NMDA receptor agonists (Koh et al., 1986; Koh and Choi, 1988; Whetsell and Christie-Pope, 1988).

The relative sparing of somatostatin-neuropeptide $Y$ (NADPH-diaphorase) neurons following QA lesions was questioned in two histologic studies, which showed a marked loss of these neurons in the centers of the lesions (Boegman et al., 1987; Davies and Roberts, 1987). We do not dispute a loss of these neurons in the lesion core, and our own studies are in accord with this. We do, however, contend that there is a relative sparing of these neurons in the transition zone, as compared with both enkephalin-immunoreactive neurons and Nissl stained neurons, following lesions with NMDA receptor agonists (Beal et al., 1986a, 1989b). The present studies show this more clearly than do studies with 1 -week survival time. At 6 months and 1 yr after the lesions there is marked striatal shrinkage, and much of the lesion core is resorbed (Zaczek et al., 1978; Isacson et al., 1985; Bjorklund et al., 1986; Roberts and DiFiglia, 1989), as shown in Figure 6. There is a relative enrichment of the transition zone in which there is partial neuronal loss and relative neuronal sparing. This results in a more striking sparing of the

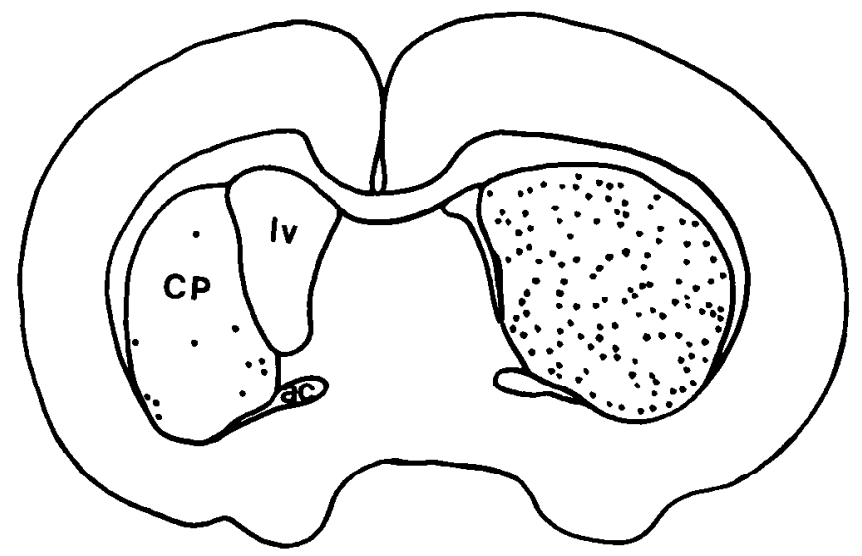

A

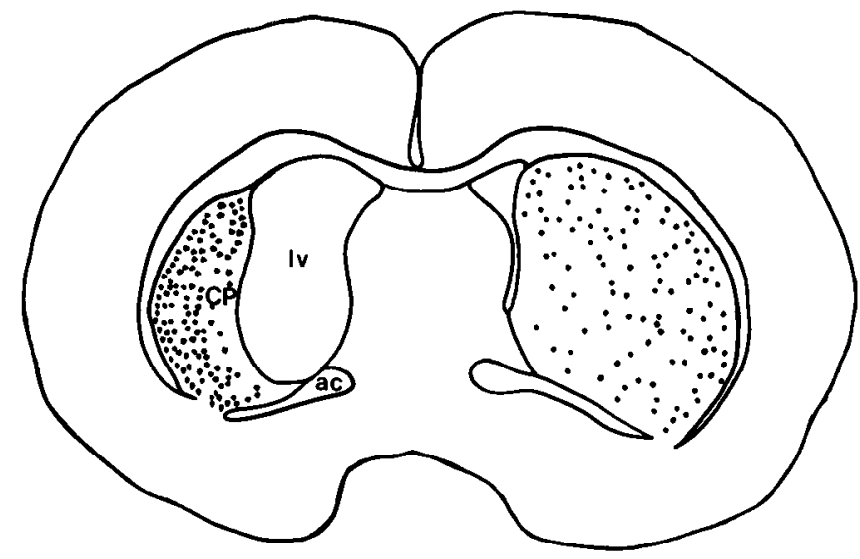

B

Figure 9. Camera lucida drawings of 1-yr KA- $(A)$ and QA-lesioned $(B)$ caudate-putamen $(C P)$ at the level of the anterior commissure $(a c)$. The left CP has been lesioned. There is a paucity of surviving NADPHdiaphorase neurons (black dots) in KA-lesioned striatum, while they are relatively spared in the QA-lesioned striatum. Note the enlarged lateral ventricle $(l v)$ in both cases.

Table 2. NADPH-diaphorase and Nissl neuron counts in the transition zone of chronic excitotoxin lesions

QA KA $\quad$ AMPA

\begin{tabular}{lccc}
\hline NADPH-diaphorase & & \\
Control & & & \\
$\quad$ Lesion & $10.0 \pm 0.6^{* *}$ & $1.3 \pm 0.1^{* *}$ & $6.2 \pm 0.3$ \\
Nissl & & & $1.4 \pm 0.2^{* *}$ \\
$\quad$ Control & $198.4+1.8$ & $186.3 \pm 4.0$ & $213.5 \pm 3.1$ \\
Lesion & $75.4 \pm 5.7^{* *}$ & $72.5 \pm 8.7^{* *}$ & $73.5 \pm 6.2^{* *}$ \\
\% NADPH-diaphorase/Nissl & & & \\
Control & $3.0 \pm 0.1$ & $3.1 \pm 0.1$ & $2.9 \pm 0.2$ \\
Lesion & $23.6 \pm 4.2^{* * *}$ & $2.9 \pm 0.7$ & $2.0 \pm 0.2$
\end{tabular}

Nine animals were examined with $\mathrm{QA}$, and four with KA and AMPA. Data are the mean \pm SEM; ${ }^{* *}, P<0.01 ; * * *$ $P<0.001$. 

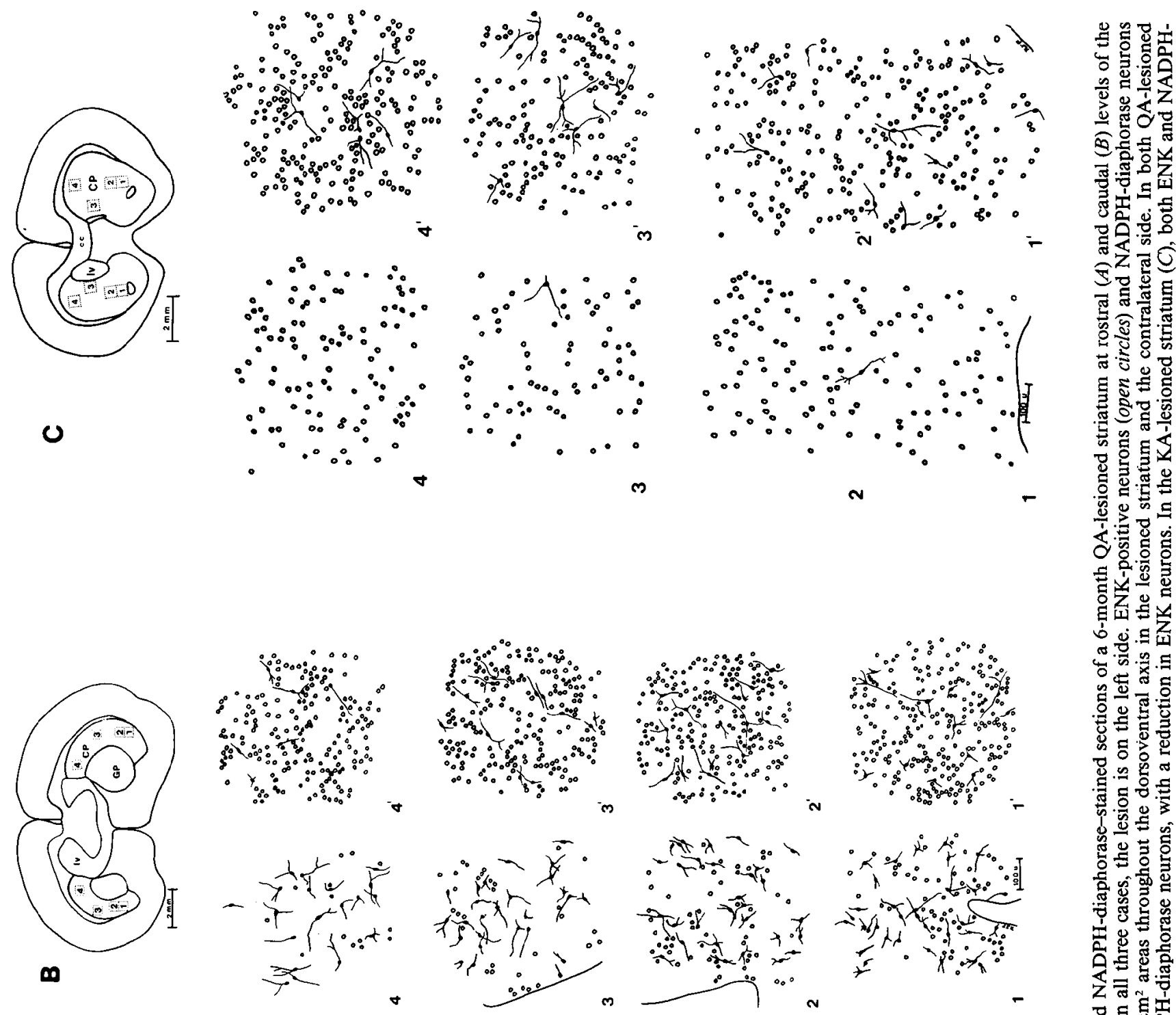

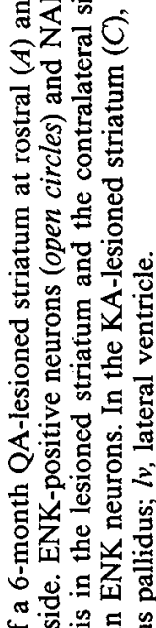

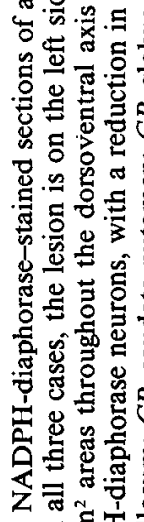

$\infty$

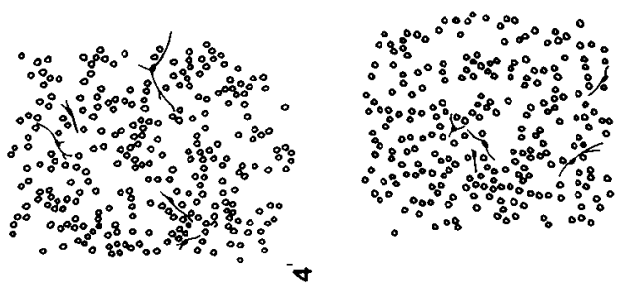

$-m$
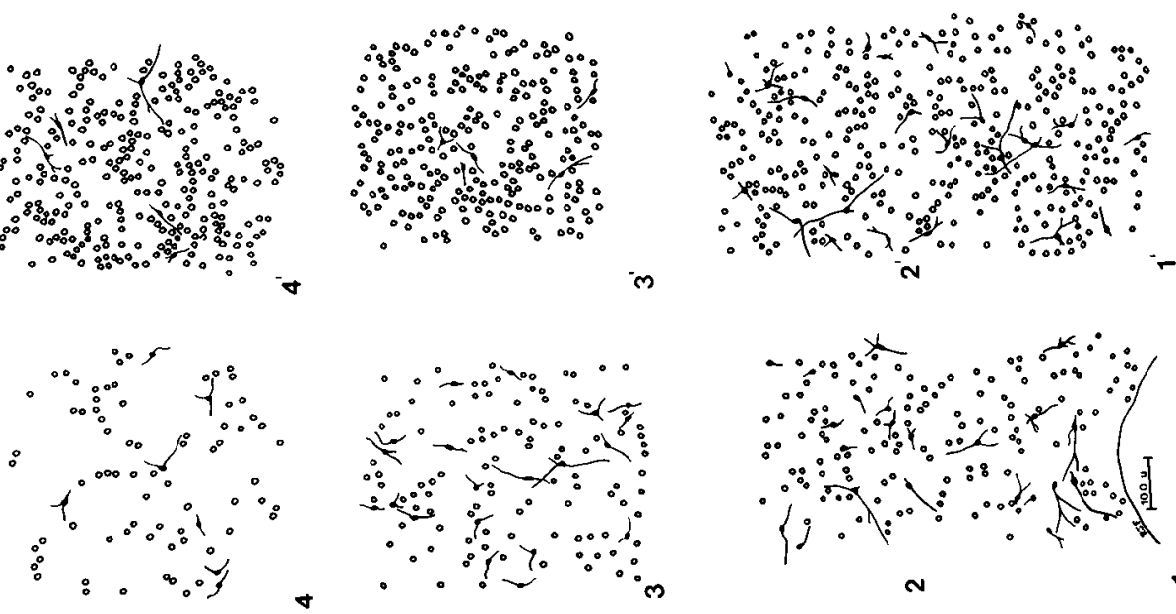

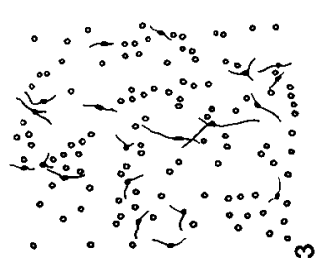

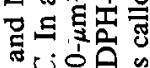

记记是

空猔

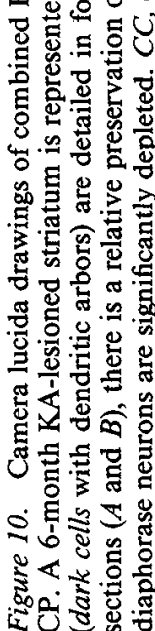

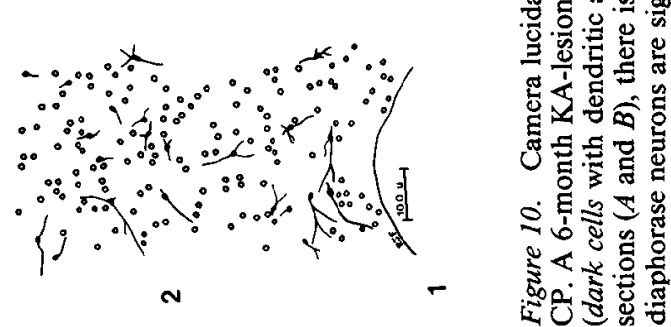


NADPH-diaphorase neurons, which are significantly increased in density within this region (Figs. 7, 9; Tables 1, 2). In contrast, no significant increase in density of NADPH-diaphorase neurons is seen following either KA or AMPA lesions. In addition to the present results, we have recently confirmed relative spring of NADPH-diaphorase neurons following NMDA agonist lesions in a double-blind study, with a novel type of lesion in which sparing occurs throughout much of the lesioned area, and with electronmicroscopy in primates (M. F. Beal, R. J. Ferrante, and P. B. Cipolloni, unpublished observations). We therefore believe that there is strong evidence to show a relative sparing of NADPH-diaphorase neurons with NMDA receptor-mediated striatal lesions. It should be emphasized, however, that even with 6-month and 1-yr lesions, there are regions of the lesions in which NADPH-diaphorase neurons are depleted. It is the areas outside the lesion core, in which the sparing of NADPH-diaphorase neurons is marked, that closely resemble HD.

One possible explanation for the sparing of NADPH-diaphorase neurons following NMDA striatal lesions is that these neurons receive fewer excitatory amino acid afferents and/or exhibit fewer NMDA receptors than other neurons. Consistent with this, a recent ultrastructural study of the neuropeptide $Y$ neurons in the striatum showed that synaptic inputs to proximal dendrites and somata were rare, as compared with neighboring neurons (Aoki and Pickel, 1989). We found that NMDA receptor-induced early gene expression is reduced in striatal NADPHdiaphorase neurons (N. W. Kowall and M. F. Beal, unpublished observations), consistent with fewer numbers of NMDA receptors. It is also possible that NADPH-diaphorase neurons could differ in calcium buffering capacity, or in ability to resist oxidative stress.

Although 1-week lesions with NMDA receptor agonists result in relative sparing of somatostatin and neuropeptide $Y$ concentrations, as compared to those of GABA and substance $P$, they do not result in significant increases in concentrations as seen in HD. At both 6 months and $1 \mathrm{yr}$, however, we observed significant increases in both somatostatin and neuropeptide $Y$ concentrations, despite significant reductions in both GABA and substance $P$ concentrations in the striatum and midbrain. In contrast, neither KA nor AMPA lesions resulted in significant increases in either somatostatin or neuropeptide $Y$ concentrations at 6 months. The finding of significant increases in somatostatin and neuropeptide $Y$ concentrations with long-term QA lesions is probably due to the increased density of surviving somatostatin-neuropeptide $\mathrm{Y}$ neurons, and perhaps afferents as well, in the shrunken striatum. Similar mechanisms may occur in HD. Although it has recently been shown that excitatory amino acids can increase somatostatin mRNA (Patel et al., 1989), it is unlikely that such an increase would persist for 6 months or 1 yr after a lesion (Meyer et al., 1988).

There were no significant changes in somatostatin, neuropeptide $Y$, substance $P$, and glutamate concentrations in cerebral cortex overlying the lesions. In HD cerebral cortex, we found small increases in neuropeptide $Y$ and somatostatin concentrations, yet no change in glutamate concentrations (Ellison et al., 1987b; Beal et al., 1988b), consistent with histologic preservation of neuropeptide $Y$ neurons and loss of pyramidal neurons (Cudkowicz and Kowall, 1990). It is unknown whether the degeneration of cortical pyramidal neurons in $\mathrm{HD}$ is a primary effect of the illness or is secondary to striatal degeneration. The present findings argue against the cortical changes being sec- ondary, because they were not observed following long-term striatal excitotoxin lesions.

It is of interest that ChAT activity remained reduced at 6 months following both QA and KA lesions. This is consistent with the results of Zaczek et al. (1978) with KA lesions at $1 \mathrm{yr}$. It is a paradoxical result because large striatal aspiny neurons containing ChAT activity are relatively spared by both QA and KA lesions at 1 week (Beal et al., 1989b; Roberts and DiFiglia, 1989). Large neurons were also spared by both types of lesions in the present study. This finding parallels our observations in $\mathrm{HD}$ in which there is a preservation of cholinergic perikarya despite a loss of ChAT activity (Ferrante et al., 1987a). The explanation for this discrepancy may be that there are retrograde changes in cholinergic axon terminals, with a consequent depletion of enzyme activity, despite preserved neuronal perikarya. A loss of ChAT axon terminals within the lesion core has been observed (Roberts and DiFiglia, 1989). The striatal cholinergic neurons are known to have extensive axonal arborizations synapsing on dendritic spines and shafts of mediumsized spiny projection neurons (DiFiglia, 1987; Izzo and Bolam, 1988 ), which may make them vulnerable to retrograde degeneration.

Neurochemical studies of HD striatum show either no alteration or small increases in DA concentrations (Spokes, 1980; Kish et al., 1987; Beal et al., 1990b). HVA concentrations are unchanged, while both 5-HT and HIAA concentrations are significantly increased (Spokes, 1980; Kish et al., 1987; Reynolds and Pearson, 1987; Beal et al., 1990b). One-week lesions with QA did not replicate these findings, because both HVA and HIAA were significantly increased, yet there were no significant changes in DA and 5-HT concentrations. Similar observations have been made at $10 \mathrm{~d}$ after QA and KA lesions (Sperk et al., 1981; Aldinio et al., 1985; Ma77ari et al., 1986). In contrast, at both 6 months and $1 \mathrm{yr}$, there were significant increases in both 5-HT and HIAA, yet no change in DA or HVA, similar to findings in HD. Because there is marked striatal shrinkage both in HD and following chronic excitotoxin lesions, the unchanged DA levels may actually represent a loss of total striatal DA, consistent with a dying back of striatal DAergic afferents (Schwarcz et al., 1980; Isacson et al., 1985), which is also seen in HD (Ferrante and Kowall, 1987). The difference between the effects of striatal lesions on DA and 5-HT may reflect synaptic contacts. Almost all DA terminals form synapses on striatal neurons (Pickel et al., 1981), whereas some 5-HT boutons do not appear to form morphologically defined synapses (Soghomonian et al., 1989). Alternatively, 5-HT terminals may be more extensively collatcralizcd, making them less susceptible to retrograde degeneration.

Although QA lesions replicate many of the neurochemical features of $\mathrm{HD}$, concentrations of $\mathrm{QA}$ are unchanged in $\mathrm{HD}$ postmortem tissue and cerebrospinal fluid (Reynolds et al., 1988; Schwarcz et al., 1988; Heyes et al., 1991). In addition, we found that lesions with NMDA receptor agonists other than QA also result in relative sparing of somatostatin-neuropeptide $Y$ neurons (Beal et al., 1989b, 1990a). We therefore view QA lesions as a model of $\mathrm{HD}$, suggesting that there may be an NMDA receptor-mediated excitotoxic process. Consistent with this, it has recently been shown that NMDA receptors are preferentially lost in HD striatum (Young et al., 1989). One potential mechanism that could result in overactivation of NMDA receptors is a deficiency of kynurenic acid, which is an antagonist at the glycine allosteric site on the NMDA receptor (Danysz et al., 
1989; Kessler et al., 1989). We recently found a significant decrease in kynurenic acid concentrations in HD putamen and cerebrospinal fluid (Beal et al., 1990b). The present results show that kynurenic acid concentrations are increased with long-term excitotoxin lesions, consistent with a glial localization (Turski et al., 1989).

Chronic (long-term) lesions with NMDA receptor agonists, such as QA, provide a neurochemical model that closely mimics the alterations observed in HD striatum. Not only is there a depletion of markers of spiny neurons (GABA and substance $P)$, but there are also significant increases in neurochemical markers of aspiny neurons (somatostatin and neuropeptide $Y$ ) and a depletion of ChAT activity, similar to changes observed in HD. In addition, the long-term lesions result in changes in monoamine concentrations identical to those seen in HD. Excitotoxin lesions are also neurochemically similar to $\mathrm{HD}$ in a number of other respects: Striatal QA lesions result in increased concentrations of neurotensin, similar to changes seen in HD (Masuo et al., 1990). Following QA lesions, there is a preferential loss of NMDA receptors as compared with non-NMDA receptors (Greenamyre and Young, 1989). There are also depletions of DA, GABA, benzodiazepine, opiate, 5-HT, and muscarinic receptors (Schwarcz et al., 1977, 1980; Hruska et al., 1978; Zaczek et al., 1978; Young et al., 1984; Joyce and Marshall, 1987), similar to findings in HD (Penney and Young, 1982; Whitehouse et al., 1985; Waeber and Palacios, 1989). In rats, motor hyperactivity and learning deficits have been observed (Sanberg et al., 1978, 1989; Mason and Fibinger, 1979; Deckel et al., 1983; Isacson et al., 1986). There are also reductions in striatal glucose metabolism (Isacson et al., 1984), as seen in HD (Young et al., 1986). We and others have recently found that excitotoxin lesions in primates result in DA agonist-inducible chorea (Kanazawa et al., 1985; Hantraye et al., 1988; Beal et al., 1989a). These similarities between lesions induced by NMDA receptor agonists and $\mathrm{HD}$ strengthen the possibility that an NMDA receptor-mediated excitotoxic mechanism may be involved in the pathogenesis of HD.

\section{References}

Aldinio C, Mazzari S, Toffano G, Kohler C, Schwarcz R (1985) Effects of intracerebral injections of quinolinic acid on serotonergic neurons in the rat brain. Brain Res 341:57-65.

Aoki C, Pickel VM (1989) Neuropeptide Y in the cerebral cortex and caudate-putamen nuclei: ultrastructural basis for interactions with GABAergic and non-GABAergic neurons. J Neurosci 9:4333-4354.

Araki M, McGeer PL, McGeer EG (1985) Differential effect of kainic acid on somatostatin, GABAergic and cholinergic neurons in the rat striatum. Neurosci Lett 53:197-202.

Arnold MA, Reppert SM, Rorstad O, Sagar SM, Keutmann HT, Perlow MJ, Martin JB (1982) Temporal patterns of somatostatin immunoreactivity in the cerebrospinal fluid of rhesus monkeys: effect of environmental lighting. J Neurosci 2:674-680.

Beal MF, Martin JB (1986) Neuropeptides in neurological disease. Ann Neurol 20:547-565.

Beal MF, Mazurek MF (1987) Substance P-like immunoreactivity is reduced in Alzheimer's disease cerebral cortex. Neurology 37:12051209.

Beal MF, Marshall PE, Burd GD, Landis DMD, Martin JB (1985) Excitotoxin lesions do not mimic the alteration of somatostatin in Huntington's disease. Brain Res 361:135-145.

Beal MF, Kowall NW, Ellison DW, Mazurek MF, Swartz KJ, Martin JB (1986a) Replication of the neurochemical characteristics of Huntington's disease by quinolinic acid. Nature 321:168-171.

Beal MF, Mazurek MF, Lorenz LJ, Chattha GK, Ellison DW, Martin JB (1986b) An examination of neuropeptide Y postmortem stability in an animal model simulating human autopsy conditions. Neurosci Lett 64:69-74.
Beal MF, Ellison DW, Mazurek MF, Swartz KJ, Malloy JR, Bird ED, Martin JB (1988a) A detailed examination of substance $P$ in pathologically graded cases of Huntington's disease. J Neurol Sci 84:5161

Beal MF, Mazurek MF, Ellison DW, Swartz KJ, MacGarvey U, Bird ED, Martin JB (1988b) Somatostatin and neuropeptide Y concentrations in pathologically graded cases of Huntington's disease. Ann Neurol 23:562-569.

Beal MF, Kowall NW, Ferrante RJ, Cipolloni PB (1989a) Quinolinic acid striatal lesions in primates as a model of Huntington's disease. Ann Neurol 26:137.

Beal MF, Kowall NW, Swartz KJ, Ferrante RJ, Martin JB (1989b) Differential sparing of somatostatin-neuropeptide $Y$ and cholinergic neurons following striatal excitotoxin lesions. Synapse 31:38-47.

Beal MF, Kowall NW, Swartz KJ, Ferrante RJ (1990a) Homocysteic acid striatal lesions spare somatostatin-neuropeptide Y-NADPH-diaphorase neurons. Neurosci Lett 108:36-42.

Beal MF, Matson WR, Swartz KJ, Gamache P, Bird ED (1990b) Multicomponent analysis of tryptophan and tyrosine metabolism in Huntington's disease: evidence for reduced formation of kynurenic acid. J Neurochem 55:1327-1339.

Bjorklund H, Olson L, Dahl D, Schwarcz R (1986) Short- and longterm consequences of intracranial injections of the excitotoxin quinolinic acid, as cvidenced by GFAP immunocytochemistry of astrocytes. Brain Res 371:267-277.

Boegman RJ, Smith Y, Parent A (1987) Quinolinic acid does not spare striatal neuropeptide Y-immunoreactive neurons. Brain Res 415:178182.

Bohlen P, Stein S, Dairman W, Udenfriend S (1973) Fluorometric assay of proteins in the nanogram range. Arch Biochem Biophys 155: 213-220.

Bruyn GW (1968) Huntington's chorea. Historical, clinical and laboratory synopsis. In: Handbook of clinical neurology, Vol 6, Diseases of the basal ganglia (Vinken PJ, Bruyn GW, eds), pp 298-378. Amsterdam: North Holland.

Coyle JT, Schwarcz R (1976) Lesion of striatal neurons with kainic acid provides a model for Huntington's chorea. Nature 263:244-246.

Cudkowicz M, Kowall NW (1990) Degeneration of pyramidal projection neurons in Huntington's disease cortex. Ann Neurol 27:200204.

Danysz W, Fadda E, Wroblewski JT, Costa E (1989) Kynurenate and 2-amino-5-phosphonovalerate intereact with multiple binding sites of the $N$-methyl-D-aspartate glutamate receptor domain. Neurosci Lett 96:340-344.

Davies SW, Roberts PJ (1987) No evidence for preservation of somatostatin containing neurons after intrastriatal injections of quinolinic acid. Nature 327:326-329.

Dawbarn D, DeQuidt ME, Emson PL (1985) Survival of basal ganglia neuropeptide Y-somatostatin neurons in Huntington's disease. Brain Res 340:251-260.

Deckel AW, Robinson RG, Coyle JT, Sanberg PR (1983) Reversal of long-term locomotor abnormalities in the kainic acid model of Huntington's disease by day 18 fetal striatal implants. Eur J Pharmacol 93:287-288.

DiFiglia M (1987) Synaptic organization of cholinergic neurons in the monkey neostriatum. J Comp Neurol 255:245-258.

Ellison DW, Beal MF, Martin JB (1987a) Amino acid neurotransmitters in postmortem human brain analyzed by high performance liquid chromatography with electrochemical detection. J Neurosci Methods 19:305-315.

Ellison DW, Beal MF, Mazurek MF, Malloy JR, Bird ED, Martin JB (1987b) Amino acid neurotransmitter abnormalities in Huntington's disease and the quinolinic acid animal model of Huntington's disease. Brain 110:1657-1673.

Ferrante RJ, Kowall NW (1987) Tyrosine hydroxylase-like immunoreactivity is distributed in the matrix compartment of normal human and Huntington's disease striatum. Brain Res 416:141-146.

Ferrante RJ, Kowall NW, Beal MF, Richardson EP Jr, Martin JB (1985) Selective sparing of a class of striatal neurons in Huntington's disease. Science 230:561-563.

Ferrante RJ, Beal MF, Kowall NW, Richardson EP Jr, Martin JB (1987a) Sparing of acetylcholinesterase-containing striatal neurons in Huntington's disease. Brain Res 411:162-166.

Ferrante RJ, Kowall NW, Richardson EP, Bird ED, Martin IB (1987b) Topography of enkephalin, substance $P$ and acetylcholinesterase staining in Huntington's disease striatum. Neurosci Lett 71:283-288. 
Fonnum F (1969) Radiochemical microassays for the determination of choline acetyltransferase and acetylcholinesterase activities. Biochem J 115:465-472.

Greenamyre JT, Young AB (1989) Synaptic localization of striatal NMDA, quisqualate and kainate receptors. Neurosci Lett 101:133137.

Hantrayc P, Riche D, Maziere M, Isacson O (1988) A primate model of Huntington's disease: behavioral and anatomical studies of unilateral excitotoxic lesions of the caudate-putamen and in the baboon. Exp Neurol 108:91-104.

Heyes MP, Swartz KJ, Markey SP, Beal MF (1991) Regional brain and cerebrospinal fluid quinolinic acid concentrations in Huntington's disease. Neurosci Lett, in press.

Hruska RE, Schwarcz R, Coyle JT, Yamamura HI (1978) Alterations of muscarinic cholinergic receptors in the rat striatum after kainic acid injections. Brain Res 152:620-625.

Isacson O, Brundin P, Kelly PAT, Gage FH, Bjorklund A (1984) Functional neuronal replacement by grafted striatal neurons in the ibotenic acid-lesioned rat striatum. Nature 311:458-460.

Isacson O, Brundin P, Gage FH, Bjorklund A (1985) Neural grafting in a rat model of Huntington's disease: progressive neurochemical changes after neostriatal ibotenate lesions and striatal tissue grafting. Neuroscience 16:799-817.

Isacson O, Dunnett SB, Bjorklund A (1986) Graft-induced behavioral recovery in an animal model of Huntington's disease. Proc Natl Acad Sci USA 83:2728-2732.

Izzo PN, Bolam JPL (1988) Cholinergic synaptic input to different parts of spiny striatonigral neurons in the rat. J Comp Neurol 269: 219-234.

Joyce JN, Marshall JF (1987) Quantitative autoradiography of quinolinic acid $\mathrm{D}_{2}$ sites in rat caudate-putamen: localization to intrinsic neurons and not to neocortical afferents. Neuroscience 20:773-795.

Kanazawa I, Tanaka Y, Cho F (1985) Choreic movements induced by unilateral kainate lesion of the striatum and $\mathrm{L}$-dopa administration in monkey. Neurosci Lett 71:241-246.

Kessler M, Terramani T, Lynch G, Baudry M .(1989) A glycine site associated with $N$-methyl-D-aspartate receptors: characterization and identification of a new class of antagoists. J Neurochem 52:13191328.

Kish SJ, Shannak K, Hornykiewicz O (1987) Elevated serotonin and reduced quinolinic acid in subregionally divided Huntington's disease striatum. Ann Neurol 22:386-389.

Koh J-Y, Choi DW (1988) Cultured striatal neurons containing NADPH-diaphorase or acetylcholinesterase are selectively resistant to injury by NMDA receptor agonists. Brain Res 446:374-378.

Koh J-Y, Peters S, Choi DW (1986) Neurons containing NADPHdiaphorase are selectively resistant to quinolinate toxicity. Science 234:73-76.

Mason ST, Fibiger HC (1979) Kainic acid lesions of the striatum in rats mimic the spontaneous motor abnormalities of Huntington's disease. Neuropharmacology 18:403-407.

Masuo Y, Montagne M-N, Pelaprat D, Scherman D, Rostene W (1990) Regulation of neurotensin-containing neurons in the rat striatum, effects of unilateral striatral lesions with quinolinic acid and ibotenic acid on neurotensin content and its binding site density. Brain Res 520:6-13.

Matson WR, Gamache PG, Beal MF, Bird ED (1987) EC array sensor concepts and data. Life Sci 41:905-908.

Mazzari S, Aldinio C, Beccaro M, Toffano G, Schwarcz R (1986) Intracerebral QA injection in the rat: effects on dopaminergic neurons. Brain Res 380:309-316.

McGeer EG, McGeer PL (1976) Duplication of biochemical changes of Huntington's chorea by intrastriatal injections of glutamic and kainic acids. Nature 263:517-519.

Meyer DK, Olenik C, Sperk G (1988) Chronic effects of systemic application of kainic acid on mRNA levels of neuropeptides in rat brain. Soc Neurosci Abstr 14:6.

Patel SC, Papachristou DN, Patel YC (1989) Quinolinic acid increases somatostatin mRNA and peptide levels in cultured rat cortical neurons. Soc Neurosci Abstr 15:935.

Penney JB, Young AB (1982) Quantitative autoradiography of neurotransmitter receptors in Huntington's disease. Neurology 32:13911395.

Pickel VM, Beckley SC, Joh TH, Reis DJ (1981) Ultrastructural immunocytochemical localization of tyrosine hydroxylase in the neostriatum. Brain Res 225:373-385.
Reynolds GP, Pearson SJ (1987) Decreased glutamic acid and increased 5-hydroxytryptamine in Huntington's disease brain. Neurosci Lett 78:233-238.

Reynolds GP, Pearson SJ, Halket J, Sandler M (1988) Brain quinolinic acid in Huntington's disease. J Neurochem 50:1959-1960.

Roberts RC, DiFiglia M (1989) Short and long-term survival of large neurons in the excitotoxic lesioned rat caudate nucleus: a light and electron microscopic study. Synapse 3:363-371.

Sanberg PR, Lehmann J, Fibiger HC (1978) Impaired learning and memory after kainic acid lesions of the striatum: a behavior model of Huntington's disease. Brain Res 149:546-551.

Sanberg PR, Calderon SF, Giordano M, Tew JM, Norman AB (1989) The UA model of Huntington's disease: locomotor abnormalities. Exp Neurol 105:45-53.

Schwarcz R, Bennett JP, Coyle JT (1977) Loss of striatal serotonin synaptic receptor binding induced by kainic acid lesions: correlations with Huntington's disease. J Neurochem 28:867-869.

Schwarcz R, Fuxe K, Hokfelt T, Tereniuis L, Goldstein M (1980) Effects of chronic striatal kainate lesions on some dopaminergic parameters and enkephalin immunoreactive neurons in the basal ganglia. J Neurochem 34:772-778.

Schwarcz R, Whetsell WO, Mangano RM (1983) Quinolinic acid: an endogenous metabolite that produces axon-sparing lesions in rat brain. Science 219:316-318

Schwarcz R, Foster AC, French ED, Whetsell WO, Kohler C (1984) Excitotoxin models for neurodegenerative disorders. Life Sci 35:1932.

Schwarcz R, Tamminga CA, Kurlan R, Shoulson I (1988) Cerebrospinal fluid levels of quinolinic acid in Huntington's disease and schizophrenia. Ann Neurol 24:580-582.

Soghomonian JJ, Descarries L, Watkins KC (1989) Serotonin innervation in adult rat neostriatum. II. Ultrastructural features, a radiographic and immunocytochemical study. Brain Res 481:67-86.

Sperk G, Berger M, Hortnagl H, Hornykiewicz O (1981) Kainic acidinduced changes of serotonin and quinolinic acid metabolism in the striatum and substantia nigra of the rat. Eur J Pharmacol 74:279_ 286.

Spokes EGS (1980) Neurochemical alterations in Huntington's chorea: a study of postmortem brain tissue. Brain 103:179-210.

Swartz KJ, Matson WR, MacGarvey U, Ryan EA, Beal MF (1990) Measurement of kynurenic acid in mammalian brain extracts and cerebrospinal fluid by high performance liquid chromatography with fluorometric and coulometric electrode array detection. Anal Biochem 185:363-376.

Turski WA, Gramsbergen TBP, Traitler H, Schwarcz R (1989) Rat brain slices produce and liberate kynurenic acid upon exposure to L-kynurenine. J Neurochem 52:1629-1636.

Vonsattel J-P, Myers RH, Stevens TJ (1985) Neuropathologic classification of Huntington's disease. J Neuropathol Exp Ncurol 44:559577

Waeber C, Palacios JM (1989) Serotonin-1 receptor binding sites in the human basal ganglia are decreased in Huntington's chorea but not in Parkinson's disease: a quantitative in vitro autoradiography study. Neuroscience 32:337-347.

Whetsell WO Jr, Christie-Pope B (1988) Relative resistance to quinolinic acid toxicity of neurons containing nicotinamide adenine dinucleotide phosphate diaphorase (NADPH-d) in cultures of rat corticostriatal system. Soc Neurosci Abstr 14:746.

Whitehouse PJ, Trifiletti RR, Jones BE, Folstein S, Price DL, Synder SH, Kuhar MJ (1985) Neurotransmitter receptor alterations in Huntington's disease: autoradiographic and homogenate studies with special reference to benzodiazepine receptor complexes. Ann Neurol 18: 202-210.

Young AB, Pan HS, Ciliax BJ, Penney JB (1984) GABA and benzodiazepine receptors in basal ganglia function. Neurosci Lett 47:361367.

Young AB, Penney JB, Starosta-Rubinstein S, Markel DS, Barent S, Giordani B, Ehrenkaufer R, Jewett D, Hichwa R (1986) PET scan investigations of Huntington's disease: cerebral metabolic correlates of neurological features and functional decline. Ann Neurol 20:296303.

Young AB, Greenamyre JT, Hollingsworth Z, Albin R, D'Amato C, Shoulson I, Penney JB (1989) NMDA receptor losses in putamen from patients with Huntington's disease. Science 241:981-983.

Zaczek R, Schwarcz R, Coyle JT (1978) Long-term sequelae of striatal kainate lesion. Brain Res 152:626-632. 